\title{
AS CONTRIBUIÇÕES DA LITERATURA INFANTIL E DA EDUCOMUNICAÇÃO PARA A CONSTRUÇÃO DE CONHECIMENTO E SUAS PERSPECTIVAS NA ERA DIGITAL
}

\author{
Luciana Nunes Garcia Ferreira ${ }^{1}$ \\ Vanice dos Santos ${ }^{2}$ \\ Jaime Farias Dresch ${ }^{3}$
}

\begin{abstract}
Resumo: A importância da literatura infantil é problematizada no sentido de se compreender a sua participação na construção do conhecimento. A base da metodologia de aprendizagem está pautada no conceito de educomunicação e em práticas pedagógicas dialógicas, colaborativas. O objetivo é refletir a respeito das contribuições da literatura infantil para a educomunicação diante das perspectivas e desafios nessa nova era, na qual a tecnologia está inserida de forma abrangente e ubíqua, chegando a colocar em questão a existência futura da literatura veiculada no formato impresso. Para isso, foram utilizados autores que abordam a temática, como Coelho (2000), Abramovich (2001), Cristófano (2010), Santaella (2003), Cabello (2014), Souza (2016), Kaplún (1998), Sartori e Kornatzki (2011), Soares (2011), constituindo-se, assim, o embasamento para a compreensão das relações entre literatura infantil, educomunicação e era digital. Pode-se considerar que as tecnologias digitais estão hoje cada vez mais presentes na vida da sociedade, cabendo aos educadores, além de valorizar a literatura impressa, também adequá-la ao mundo digital, como ocorrido em todas as outras eras culturais, na qual, cada cultura ia coexistindo da forma tradicional ou conciliada com a nova cultura.
\end{abstract}

Palavras-chave: Literatura infantil. Educomunicação. Era digital. Tecnologias

\section{THE CONTRIBUTIONS OF CHILDREN'S LITERATURE AND EDUCOMMUNICATION TO CONSTRUCTION OF KNOWLEDGE AND ITS PERSPECTIVES IN THE DIGITAL AGE}

\begin{abstract}
The importance of children's literature is problematized in the sense of understanding their participation in the construction of knowledge. The basis of the learning methodology is based on the concept of educommunication and pedagogical dialogic, collaborative practices. The objective is to reflect on the contributions of children's literature
\end{abstract}

\footnotetext{
${ }^{1}$ Mestranda do Programa de Pós-Graduação em Educação da Universidade do Planalto Catarinense, Av. Castelo Branco, 170 - Universitário - Lages - SC - Brasil - CEP 88509-900. E-mail: lununes@uniplaclages.edu.br

2 Doutora em Educação (UFRGS), Mestre e Licenciada em Educação (UNISINOS). Docente pesquisadora no Programa de Pós-Graduação em Educação da Universidade do Planalto Catarinense (UNIPLAC), Av. Castelo Branco, 170 - Universitário - Lages - SC - Brasil - CEP 88509900. E-mail: vanicedossantos@gmail.com.

${ }^{3}$ Doutor em Educação, docente do Programa de Pós-Graduação em Educação da Universidade do Planalto Catarinense (UNIPLAC), Av. Castelo Branco, 170 - Universitário - Lages - SC - Brasil - CEP 88509-900. E-mail: prof.jaime@uniplaclages.edu.br
}

Criar Educação, Criciúma, v. 8, ㄲo1, jan/jul 2019.- PPGE - UNESC 
to educommunication in the face of the perspectives and challenges in this new era, in which the technology is inserted in a comprehensive and ubiquitous way, even calling into question the future existence of the printed literature. For this, authors that approach the subject were used, such as Coelho (2000), Abramovich (2001), Cristófano (2010), Santaella (2003), Cabello (2014), Souza (2016), Kaplún (1998), Sartori and Kornatzki (2011), Soares (2011), thus constituting the basis for understanding the relationship between children's literature, educommunication and the digital age. It can be considered that digital technologies are nowadays increasingly present in the life of society, and it is up to educators, in addition to valuing printed literature, to adapt it to the digital world, as it has occurred in all other cultural eras, each culture co-existed in the traditional way or reconciled with the new culture.

Keywords: Children's Literature. Educommunication. Digital age. Technologies.

\section{INTRODUÇÃO}

Os contos vem há muito tempo fazendo parte da cultura humana. Lendas e histórias são passadas de geração para geração representando as experiências e os hábitos de cada sociedade. Inicialmente essa difusão acontecia de forma verbal, porém, com o passar do tempo, surgiu a oportunidade do homem registrar estas histórias. Então, as obras literárias passaram a ser transmitidas de forma manuscrita e, posteriormente, impressa, transformando-se num dos principais veículos de disseminação das tradições e legados da sociedade.

Em seu estudo sobre as eras culturais, Santaella (2003) aborda as fases destas transformações que ocorreram no decorrer da evolução do homem, dividindo estes períodos de transições em seis eras culturais: primeiramente, a cultura oral, que diz respeito ao desenvolvimento da linguagem verbal do homem, posteriormente, o surgimento da cultura escrita. Em seguida, o aparecimento da cultura impressa, com a invenção da imprensa, mais adiante, a cultura de massa, com a criação do rádio e da televisão, e após, há o surgimento da cultura das mídias, com vídeos, vídeo games e, por fim, a cultura digital, que com todas as tecnologias digitais está cada vez mais inserida na vida da sociedade. Baseado nessa classificação, feita pela semioticista, é possível relacionar o surgimento da literatura já na era da cultura oral, quando as histórias eram repassadas em rodas de conversa ou de pessoa para pessoa em forma de narrativas. Posteriormente, o registro destes contos e, em seguida, a sua impressão, veio a se espalhar pelo mundo, disseminando conhecimento e cultura entre povos.

Criar Educação, Criciúma, v. 8, ํo1, jan/jul 2019.- PPGE - UNESC 
A evolução da humanidade acontece conscientemente na medida em que cada sujeito vai assimilando desde a infância os ensinamentos e experiências de seus antepassados. Para Coelho (2000), as literaturas, principalmente a infantil, tem a tarefa de transformar a sociedade, agindo na formação, espontânea ou estimulada, pelo meio escolar, o convívio e o diálogo entre o leitor e o texto literário. Portanto, a literatura é uma forma eficaz de ler o mundo.

A literatura infanto-juvenil é a primeira forma escrita de contato da criança e do jovem com as tradições culturais e literárias de seu povo. Ao mesmo tempo que promove recreação também cultiva valores necessários à vida em sociedade e favorece o raciocínio e a inteligência da criança e do jovem. Ela pode significar também uma evasão, se os elementos da fantasia e imaginação estiverem presentes. Sua função primeira é despertar, na criança e no jovem, o gosto pela leitura e permitir-lhe um contato com a realidade que o cerca (SOUZA, 2006, p. 53).

Como afirma Coelho (2000), a literatura é a arte da comunicação, produto da imaginação e da criatividade, uma forma de linguagem tão intensa que pode representar o desenvolvimento de um povo. Nesse sentido, Campos (2005, p. 11) afirma que "o texto literário possibilita ao indivíduo olhar para o outro e nele reconhecer-se; este ato contribui para a criação da sua identidade".

Para Abramovich (2001), a literatura é importantíssima para a formação do sujeito; ouvindo histórias a criança vai criando gosto pela leitura e iniciando no mundo das letras. As histórias provocam sentimentos, levam o leitor a envolver-se emocionalmente no conto. Possibilitando, assim, o aprimoramento da imaginação, da criatividade, desenvolvendo as noções para solução de seus próprios dilemas.

Além de tratar a respeito das questões da formação humana, Cristófano (2010), acrescenta que a literatura infantil também aborda as angústias da vida, as divergências, a necessidade de afeto, os sentimentos de rejeição, de solidão e os temores, dando apoio no amadurecimento afetivo da pessoa. Agindo no seu inconsciente, a literatura auxilia o leitor a lidar com suas inquietações mais profundas. Por isso, Coelho (2000) aponta a relação com a psicanálise:

Lembra a psicanálise que a criança é levada a se identificar com o herói bom e belo, não devido a sua bondade ou beleza, mas por sentir nele a própria personificação de seus problemas infantis: seu inconsciente desejo de bondade e beleza e, principalmente, sua necessidade de segurança e proteção. Identificada com os heróis e as heroínas do mundo do

Criar Educação, Criciúma, v. 8, nº1, jan/jul 2019.- PPGE - UNESC 
maravilhoso, a criança é levada, inconscientemente, a resolver sua própria situação - superando o medo que a inibi e ajudando-a a enfrentar os perigos e as ameaças que sente a sua volta e assim gradativamente, poder alcançar o equilíbrio adulto (COELHO, 2000. p. 55).

É possível observar como a literatura tem fundamental papel na formação da criança, tanto em relação à noção de moralidade e ética, de saber lidar com seus próprios sentimentos, quanto no desenvolvimento do gosto pela leitura, da criatividade e da imaginação. Segundo Cristófano (2010), tirar da criança o direito a conviver com o universo da literatura infantil, expropriando-a do mundo da fantasia e da imaginação, pode limitar a sua capacidade de sonhar e de criar.

\section{AS CONTRIBUIÇÕES DA LITERATURA INFANTIL E DA} EDUCOMUNICAÇÃO PARA A CONSTRUÇÃO DE CONHECIMENTO

A literatura infantil, mediada pelo professor por meio da comunicação, pode, segundo Sartori e Kornatzki (2011), instigar um olhar investigativo por parte do leitor, possibilitando uma educação transformadora e libertadora. Assim, ambos, professor e aluno, recebem e reconstroem a informação, convertendo-as em conhecimento. Segundo as autoras, a literatura infantil pode ser apontada como um dispositivo educomunicativo quando, por meio de práticas pedagógicas reflexivas, possibilita o desenvolvimento da criticidade.

[...] a especificidade da Literatura Infantil está no fato de que é um conteúdo educativo, expresso por texto e imagem, em alguns casos também por som, que provoca o desenvolvimento cognitivo e emocional de seu receptor, mas que também se relaciona ao seu produtor no que se refere às intenções comunicativas, expressivas, aos seus objetivos artísticos e educacionais (SARTORI; KORNATZKI, 2011, p. 3).

Diante disso, é possível traçar um paralelo entre as possibilidades educativas da literatura infantil e o conceito de educomunicação, já que, como afirma Soares (2003), as perspectivas educomunicativas visam à construção de conhecimento coletivo, colaborativo, por meio do diálogo. Com a mediação do professor, as mídias e as redes de informações podem ser utilizadas de forma crítica e criativa, como um meio ao conhecimento, cooperando na formação da personalidade e do caráter do sujeito.

Criar Educação, Criciúma, v. 8, ㄲo1, jan/jul 2019.- PPGE - UNESC 
Para Soares (2011), a educomunicação é uma prática em ascensão, em que se objetivam a renovação das práticas sociais, por meio da ampliação da expressão comunicativa e do envolvimento da juventude em seu próprio processo educativo. Por meio do aprimoramento das práticas comunicativas entre alunos e professores no ambiente escolar, é possível trabalhar na direção de levar os educandos a apoderar-se das linguagens midiáticas, sejam tecnológicas ou literárias, por exemplo, para aprofundar conhecimentos, visando promover a transformação da vida a sua volta.

Ambientes educativos devem ser espaços de formação do ser humano, da consciência e da leitura de mundo, espaços libertadores, direcionadores, de aprendizagem, onde a comunicação deveria ser o principal gatilho para a construção do conhecimento e onde as mídias e as tecnologias sejam os dispositivos auxiliares desse processo.

Kaplún (1998) afirma que não basta tentar modernizar o ensino com inovações tecnológicas se, em sua essência, a educação continua tradicional e inflexível e, na qual, as mídias são utilizadas com o propósito de reforçar a absorção dos conteúdos. Para o autor, a utilização de novas tecnologias representa uma atitude profícua quando utilizadas em prol da construção do conhecimento, trabalhadas de forma crítica, dialógica, compartilhando e reelaborando ideias, vivenciando a verdadeira aprendizagem de forma que esta não seja esquecida.

No que diz respeito às práticas educativas dialógicas e reflexivas, Souza (2016) observa que estas vêm sendo articuladas e implementadas há alguns anos, novos métodos e convicções vêm sendo aplicados no sistema de ensino, em grande parte, com a utilização das mídias e das tecnologias digitais. Segundo Cabello (2014), a expansão das tecnologias digitais está acontecendo de forma vertiginosa e a interatividade está regularmente presente na vida das pessoas. Desde muito cedo, as crianças convivem com aparatos tecnológicos e os manuseiam com extrema habilidade.

Souza (2016) destaca que os avanços tecnológicos, midiáticos e comunicacionais vêm abrindo novos caminhos de aprendizagem na comunidade escolar, possibilitando práticas de construção coletiva de conhecimento e impondo Criar Educação, Criciúma, v. 8, ํo1, jan/jul 2019.- PPGE - UNESC 
novos desafios ao âmbito educacional. Propiciando novas formas de sentir e pensar, novas formas de aprender e ensinar. Inserindo professor e aluno no mundo das tecnologias digitais.

Como afirma Arruda e Portal (2012), o processo de aprendizagem não é mera transmissão de conhecimento, mas sim, a construção que acontece entre professor e aluno, num processo de mediação contínuo, por meio da reflexão e da comunicação. Supõe-se não ser possível que o educador seja mediador daquilo que ele próprio não conhece ou que tem pouquíssima habilidade, o que demostra a necessidade do professor de estar continuamente se atualizando.

Para que o educador possa utilizar-se destas tecnologias como dispositivo à construção do conhecimento de forma eficaz e prazerosa, Cabello (2014) pontua que é necessário que ele próprio saiba manipulá-las com habilidade, clareza e eficácia, de forma a ampliar suas formas de comunicação e expressão. Assim, a importância de todos, nos ambientes educativos, estarem incluídos no mundo digital, possibilitando a superação das dificuldades no uso de tecnologias, o que é imprescindível diante de tantas evoluções tecnológicas a que a sociedade de hoje está sendo submetida. As possibilidades do uso das tecnologias para o aprimoramento nas práticas educativas e para a qualidade de vida de modo geral, são vislumbradas por muitos estudiosos do meio. Para tanto, é necessário que o educador saiba utilizá-las, modificando-as e adaptando-as às próprias necessidades, promovendo ações de ensino e aprendizagem colaborativas e participativas, propiciando a compreensão do mundo de forma a agir e transformar a sociedade.

De acordo com Almeida (2016), a utilização das mídias digitais deve ser dirigida de forma a trazer benefícios à educação de jovens, crianças e até mesmo dos adultos. Portanto, tendo como propósito a educação, a construção do conhecimento, o desenvolvimento do senso crítico, a formação da cidadania, o respeito às diferenças e a construção de um mundo melhor, pode-se dizer que as tecnologias e a literatura podem fornecer grande contribuição nesse processo. 
Como enfatizado em inúmeros estudos, a literatura possibilita, de forma eficaz, o desenvolvimento e aprimoramento da percepção de mundo na criança, além de auxiliar na formação integral do sujeito. Porém, preocupações surgem a respeito da possível crise à que a literatura pode estar sendo submetida, inicialmente com o surgimento da cultura de massa e, posteriormente, com a cultura digital. Martín-Barbero (2014) afirma que a crise do livro e da leitura está relacionada às mudanças culturais, uma vez que jovens e crianças estão tão imersos na cultura audiovisual que acabam por deixar a literatura esquecida.

No entanto, contrariando as análises mais pessimistas acerca da literatura infantil, é possível encontrar expectativas mais promissoras sobre o assunto, apoiando-se, por exemplo, nos estudos de Santaella (2003). Para a autora, a cada surgimento de uma nova era cultural, a cultura anterior, apesar de parecer estar ameaçada, permanece ativa, e a nova cultura, conquistando seu próprio espaço, estabelece uma relação de entrelaçamento cada vez mais complexo com a cultura anterior. Demonstra, assim, que todas as culturas vão interagindo com as demais, permanecendo atuantes em sua forma original ou adaptando-se às novas realidades.

Desta forma, mesmo diante de inúmeros questionamentos sobre a possibilidade de haver ou não espaço para a literatura ou para a literatura infantil nesse mundo, onde as tecnologias se difundiram com tanta intensidade, Coelho (2000) afirma que a literatura continua muito presente nessa época de informação e comunicação instantânea.

Mesmo estando hoje na era da imagem e do som, é possível afirmar que existem sim espaços para a literatura infantil, pois esta continua ainda sendo um importante instrumento no processo educativo, estando presente na forma impressa, mas também na forma digitalizada, podendo ser encontrada também em espaço como da web. A existência de diversos sites e blogs que divulgam histórias de todos os tipos, como: Turma da Mônica ${ }^{4}$, Planetinha ${ }^{5}$, Leiturinha ${ }^{6}$ entre outros,

\footnotetext{
${ }^{4}$ http://turmadamonica.uol.com.br/quadrinhos/

5 http://www.planetinha.com.br/era-uma-vez
}

Criar Educação, Criciúma, v. 8, nº1, jan/jul 2019.- PPGE - UNESC 
demonstram o empenho de muitos educadores pela adaptação da literatura infantil às novas realidades tecnológicas, possibilitando aos professores estimular nas crianças o gosto pela leitura, utilizando os dispositivos que mais as interessar. Bergomás (2014), constata que a web é um espaço para estabelecer relações, protagonizando o uso das informações em prol da construção do conhecimento, onde é possível se expressar, desenvolver atividades de forma interativa, participativa e colaborativa.

As possibilidades para a literatura infantil vêm cada vez mais se ampliando, o que antes só era possível ser encontrado em livros impressos, está agora disponível em muitos formatos, como em livros digitais (ebooks), em cds rom, em livros brinquedos, na web, entre outros, proporcionando ao leitor a possibilidade de escolha. Da mesma forma, as tecnologias impressionam pela velocidade com que estão evoluindo e pelas possibilidades que disponibilizam ao ser humano. Para algumas pessoas, essas mudanças são a esperança de um mundo melhor, na perspectiva de facilitar o acesso à outros lugares, sem que seja necessário dirigir, deixando o tempo de locomoção disponível para outras atividades, assim como ter ao seu alcance obras de literatura sem que seja necessário ir à biblioteca ou às livrarias, são possibilidades que entusiasmam multidões.

\section{CONSIDERAÇÕES FINAIS:}

Tendo em vista os aspectos observados, pode-se constatar que, são inúmeras as possibilidades de construção de conhecimento por meio da literatura infantil e de práticas educomunicativas, essa aprendizagem pode ser alcançada por meio da fantasia, da imaginação, tendo como suporte a comunicação e a reflexão, isso faz com que a literatura infantil esteja diretamente ligada aos ideais educomunicativos, já que a educomunicação também objetiva as práticas pedagógicas comunicativas e reflexivas, na qual a construção de conhecimento acontece de forma coletiva e colaborativa, tendo a tecnologia como um aporte

\footnotetext{
6 http://www.leiturinha.com.br/
}

Criar Educação, Criciúma, v. 8, nº1, jan/jul 2019.- PPGE - UNESC 
eficiente à aprendizagem. Além disso, percebe-se que é um equívoco considerar a literatura infantil ameaçada pelo avanço tecnológico, pois é possível que a própria tecnologia seja aliada à literatura, de forma a renovar os métodos de narrativas e de elaborações de histórias, de viajar no mundo da fantasia e da imaginação, e de aprender de forma divertida e prazerosa. Compreende-se, portanto, que as tecnologias estão facilitando e melhorando a vida das pessoas, e cabe ao professor usá-las em prol do desenvolvimento da cultura e da construção de conhecimento, de forma a melhorar a sua vida e dos seus semelhantes. Assim, a literatura, a educomunicação e as tecnologias digitais juntas, mediadas pelos educadores, podem contribuir para a construção coletiva de conhecimento e levar o educando a mudar o seu futuro e o da sociedade.

\section{REFERÊNCIAS:}

ALMEIDA, Lígia Beatriz Carvalho de. Projetos de intervenção em educomunicação. 2016. Disponível em: <https://docslide.com.br/download/link/projetos-de-intervencao-emeducomunicacao-as-areas-de-intervencao>. Acesso em: 11 jul. 2017.

ABRAMOVICH, Fanny. Literatura infantil: gostosura e bobices. 2. ed. São Paulo: Scipione, 2001.

ARRUDA, Marina Patrício; PORTAL, Leda Lísia Franciosi. Saberes e fazeres docentes: o dilema da reforma do pensamento e da prática pedagógica do educador do século XXI.

Percursos, Florianópolis, v. 13, n. 01, p. 199-210, jan./jun. 2012. Disponível em: <http://www.periodicos.udesc.br/index.php/percursos/article/view/2369>. Acesso em: 09 mai. 2017.

BERGOMÁS, Gabriela A. Nuevas Relaciones con el conocimiento. In: Educomunicação e Criação de Ecossistemas Comunicativos: Diálogo sem Fronteiras / (organizado por) Ademilde Sartori. Florianópolis: DIOESC, 2014.

CABELLO, Roxana. Tecnocultura escolar: hacia uma efectiva inclusión digital. In: SARTORI, Ademilde (Org.). Educomunicação e criação de ecossistemas educomunicativos: diálogo sem fronteiras. Florianópolis: DIOESC, 2014.

CAMPOS, Maria Inês Batista. Ensinar o Prazer de Ler. São Paulo: Olho d'Água, 2005.

COELHO, Nelly Novais. Literatura Infantil: teoria análise didática. 7. ed. São Paulo: Moderna, 2000.

CRISTÓFANO, Sirlene. A literatura e as novas tecnologias: a formação de leitores ativos em múltiplos suportes. Darandina Revisteletrônica, Juiz de Fora, v. 3, n. 1, p. 01-13, nov. 2010. Disponível em: <http://www.ufjf.br/darandina/files/2010/12/A-Literatura-e-as-NovasTecnologias-A-Forma\%c3\%a7\%c3\%a3o-de-Leitores-Ativos-em-M\%c3\%baltiplos-

Suportes.pdf>. Acesso em: 15 fev. 2018.

KAPLÚN, Mario. Una pedagogía de la comunicación. Madrid: Ediciones de la Torre, 1998.

Criar Educação, Criciúma, v. 8, nº1, jan/jul 2019.-PPGE - UNESC 
MARTÍN-BARBERO, Jesús. A Comunicação na Educação. Tradução de Maria Immacolata Vassallo de Lopes e Dafne Melo. São Paulo: Contexto, 2014.

SANTAELLA, Lúcia. Da cultura das mídias à cibercultura: o advento do pós-humano. São Paulo: Paulos, 2003.

SARTORI, Ademilde Silveira; KORNATZKI, Luciana. Literatura infantil e educomunicação: relações para pensar seu uso no espaço escolar. V Simpósio Nacional ABCiber, Florianópolis, nov. 2011, UDESC/UFSC. Disponível em: <https://abciber.org.br/simposio2011/anais/Trabalhos/artigos/Eixo\%201/14.E1/386-644-1-

RV.pdf> Acesso em: 27 out. 2017.

SOARES, Ismar de Oliveira. Educomunicação: o conceito, o profissional, a aplicação. São Paulo: Paulinas, 2011.

SOUZA, Edemilson Gomes de. A prática pedagógica educomunicativa como estímulo ao diálogo da comunidade escolar: aprendizagem colaborativa e protagonismo juvenil. Recife: Centro de Convenções de Pernanbuco, 2016. 5 Congresso Marista de Educação. Disponível em: <http://www.congressomarista.com.br/wp-content/uploads/2016/10/0061.pdf> Acesso em: 21 fev. 2018.

SOUZA, Glória Pimentel Correia Botelho de. A literatura infanto-juvenil brasileira vai muito bem, obrigada! São Paulo: DCL, 2006.

Recebido em dezembro 2018 Aprovado em março 2019

Criar Educação, Criciúma, v. 8, ํo1, jan/jul 2019.- PPGE - UNESC 